\title{
THE VULNERABILITY OF THE SEAMS AND JOINTS OF ADJACENT FORMATIONS
}

\section{Helmoed-Römer Heitman}

The seam between the zones of influence of adjacent formations is one of the weakest parts of any defence. Its weakness results from the situation of divided command which almost inevitably exists there. Thus any attack onto the joint and/or along the seam will cause and enjoy a far greater measure of command and control confusion among the defenders - not least of the order, counter-order variety - than would one elsewhere.

This problem of the defence is aggravated under conditions of mobile or columnar operations. Primary factors operating here are the lack of continuous close personal contact between the neighbouring formations; a natural reluctance to patrol too close to inter-formation boundaries for fear of accidental clashes with friendly forces and the equally natural tendency of forces engaged in columnar operations to cluster along their central axis. *

This potential weakness in a defence is naturally equally well known to an attacker. As a result, much energy is often expended in an effort to locate and identify the joints and seams of a defence. Once this has been achieved and other factors allowing, the attacker will then tend to concentrate on one of these weak points, attacking onto a joint and/or along a seam with his Schwerpunkt. Well handled and maintaining a high rate of advance, such an attack can sweep forward in a self-created bubble of virtual immunity for some time - often at least to the full depth of the seam being exploited. Should this amount to the full depth of the defence, the results can be readily imagined. **

In southern Africa this problem of the defence reaches a dimension all its own: A major feature of the topography here is quite simply the relative scarcity of readily visible and identifiable topographic features. Coupled with the fact of a wide-meshed road net, this leads to a not unnatural tendency to see prominent roads as ideal inter-formation boundaries - they do, after all, meet one of the most important requirements of boundaries per se: they are easily recognisable and identifiable both on the map and on the ground. Another factor to consider is that the force: space ratio in any likely conventional or semi-conventional conflict in this region will tend to push the antagonists into a columnar style of warfare. ${ }^{* \star \star}$

These very same factors - the relative lack of readily identifiable topographic features, the wide-meshed road net and the tendency to columnar operations - will tend to force the attacker to:

1. Move his 'Schwerpunkt' along a primary road' and

2. Carefully scrutinise all roads in the area of his advance in order to assess their manouvre and logistic potential.

Thus we find a situation where, as often as not, we will have deliberately - if unknowingly placed the weakest part of our defence where, at best, the enemy's reconnaissance cannot fail to locate it. At worst, the enemy's 'Schwerpunkt' will in any event be intended to move through that area. It will be readily apparant that we thus find ourselves possessors of a very dangerous habit indeed, one that we will do well to rid ourselves of.

Having said that, it is difficult to suggest viable alternatives to our existing tendency to use roads as boundaries. One might lie in a return to the more frequent use of pickets in this role and/or placing boundaries several kilometres to one side of the road. But even having selected a more sensible boundary, this will still be the weakest point of the defence, even if not as readily visible to the attacker as before. We must, therefore, begin serious consideration of ways in which to reduce the vulnerability of the seam area of the defence.

One possibility here might lie in the creation of a form of 'sandwich strip' between formations. Such a strip could then be controlled by light armoured forces under the command of the next higher headquarters for the normal course of events. Liaising continuously with both of the neighbouring formations, this force could effectively close the surveillance gap. 
The actual countering of an attack on the seam area would ideally devolve upon one of the neighbouring formations according to prior arrangement or, preferably, by SOP. This would also have to make provision for the assigned formation then automatically assuming operational control of those of its neighbour's units adjacent to the enemy penetration/advance. Such an automatic system coupled with a continuous consideration of the changing factors involved could go some way towards reducing the danger inherent in the enemy's identification and exploitation of joints and seams.

Another possibility would be to provide for a tactical headquarters to assume responsibility for such a penetration. This headquarters would then have to assume temporary command of the units on either side of the seam being exploited as well as having a part if the next higher command levels reserve assigned to it. Ideally, it would fall directly under that level, leaving the formations on either side of the penetration to carry on with their primary tasks, albeit minus some of their units.

At first glance, however, systems such as those outlined above may appear perhaps a little complicated. They are therefore put forward here merely as a stimulus for further thought in this direction. ${ }^{\star \star \star *}$

A related problem lies in the lesser but nevertheless also present and worrying tendency to 'balcony out' one formation's sector in front of part of the neighbour's. While this no doubt is only done when it is on sound tactical grounds, it always represents an added source of complication and potential danger. One need merely consider the potential of a driving attack across the front of the parent formation at an angle and on to the 'balcony'. This would not even need to be intentional to be disastrous. The elements in the 'balcony' would be deprived of support and would be driven back into the neighbouring formation's sector - in all probability intermingled with the leading enemy elements. The resultant confusion - chaos would be more apt - can be readily imagined.

The only solution here is to keep boundaries vertical wherever at all possible - even at the cost of apparent advantages to be gleaned from a 'balconied' structure of the defence. This would, after all, be in accordance with the most important of all the principles of war - keep it simple. Where 'balconying' is unavoidable, such a 'balcony' should then at least be given sufficient depth to allow for a truely mobile response to attack. Also constant liaison and a system of SOPs will be needed to cover the various eventualities - much more so than in the normal course of events.

In time of war, our inter-formation boundaries seen by him as joints and seams in our defence - - will be the subject of constant interest and fascination to the enemy. We should find them at least equally interesting, not least now, in time of peace. Then it may be possible to reward his interest with a surprise or two. If we do not now begin to concern ourselves with the problems of the seam, there will be no surprises for either side in the rapidity of the enemy's advance.

\footnotetext{
"Normally a mobile defence might be expected to be less vulnerable to a penetration along one of its seams. This would, however be dependant upon excellent surveillance, flexible command and logistics and a reasonably tight high capacity road net. Failing these it would in all probability prove difficult in the extreme to regroup and manoeuvre swiftly enough to effectively counter a fast moving penetration.

** This was, more often than is perhaps realized, the 'secret' behind some of the German army's successes. The Soviets, too, put much effort into the locating and identifying of joints and seams in the German defence.

*** Resulting, therefore, in very deep, almost totally unprotected flanks and an open rear area.

$\star \star \star \star$ Careful consideration' of the potential problems of the seam in COIN OPS should also repay the effort put into it. That, however, is beyond the scope of this paper.
}

Note:

Inter-unit seams, too, are vulnerable. Here, however, more frequent personal contact can considerably reduce the potential danger. The exploitation of such seams is also more readily countered by the parent formation. 